\title{
O Estado: segurança e insegurança ${ }^{1}$
}

\author{
Homero Santiago
}

Universidade de São Paulo

1 Este é o texto-base de uma aula proferida no concurso de livre-docência em "Filosofia geral" realizado no Departamento de Filosofia da USP em maio de 2012. O trajeto um pouco esquemático explica-se por sua essa circunstância. Limitamo-nos a desdobrar algumas alusões, precisar e umas poucas vezes atualizar as referências bibliográficas, dar ao material um título que é o mesmo do ponto então sorteado.

\section{discurso $45 / 2$}



Como sabemos, a instituição Estado vai mal das pernas. Num pastiche do que Michel Foucault certa vez afirmou sobre o homem, talvez calhasse vaticinar: o Estado é uma invenção recente que, se ainda não morreu, está prestes a alcançar seu fim - muito provavelmente por irrelevância. De fato, embora as definições, as concepções de Estado variem bastante, um dos elementos mais pregnantes de nosso correntio é o parecer de que Estado, nascido no alvorecer da modernidade para tornar-se a mais importante das instituições políticas modernas, encontra-se em franco declínio no período da globalização. Fala-se na necessidade de diminuir o raio de ação do Estado, em desmonte do Estado, em sua incapacidade para regular a economia, e assim por diante. Para não ficarmos no vazio das ideias anônimas, convoquemos dois pontos de vista que, sem embargo de seus pressupostos teóricos diversos, exprimem essa mesma tese forte do senso comum hodierno.

Primeiramente, o alentado estudo de Martin van Creveld (2004), professor da Universidade Hebraica de Jerusalém, intitulado Ascensão e declínio do Estado e cuja publicação original é de 1999. Após um longuíssimo trajeto que vai das organizações tribais a nossos dias, conclui-se o irreversível declínio do Estado. Processo que não seria por si só ruim. "Pode haver até algumas regiões e alguns países que continuem a vegetar como sempre fizeram, sem acompanhar o ritmo acelerado das mudanças". Mas a novidade, pondera o autor, haverá de ser favorável a muitos. "É, sobretudo, uma questão de disposição para descartar as antigas certezas e adaptar-se ao admirável mundo novo que nos aguarda. Em alguns lugares a mudança será pacífica. O resultado será uma prosperidade sem precedentes, quando as fronteiras nacionais se tornarem menos importantes, a tecnologia progredir, as oportunidades econômicas se abrirem e os transportes e as comunicações permitirem que diversas culturas fecundem umas às outras" (Van Creveld, 2004, p. 602).

Uma visão não tão bela mas que por outras vias apresenta similar diagnóstico de declínio do Estado é a encontrada no italiano Antonio Negri, que desde a década de 6o se revelou um ar- 
guto e persistente analista da forma-Estado e já ao início dos anos 70 identificara a crise do que então nomeava "Estado-plano" e a sua consequente transformação em "Estado-crise" (Negri, 2006, p. 39). Pois o desfecho dessa crise consumar-se-ia em nossa época, graças à globalização. Segundo Império, livro de 2000 de autoria de Negri e do americano Michael Hardt, a globalização das trocas produziu um "mercado global" e "circuitos globais de produção" que deram forma a uma nova lógica e estrutura de comando e, sobretudo, a um novo tipo de supremacia, o qual hoje compete com a soberania dos tradicionais Estados-nação. A soberania nacional viria paulatinamente diminuindo, sempre a demonstrar um menor poder regulador relativamente ao capital, que concomitantemente se fortalece ao juntar-se ao Estado e dobrá-lo desde dentro. "O declínio dos Estados-nação é, num sentido profundo, a plena realização da relação entre o Estado e o capital" (Hardt, Negri, 2005a, p. 256). ${ }^{1}$

Estão aí duas análises importantes que fornecem uma moldura mais precisa a algo que, reiteremos, faz já algum tempo ingressou com força no senso comum bem pensante: a certeza do declínio da instituição estatal. Isso a ponto de não poucas vezes justificar o desinteresse (quando não o menosprezo) pelo tema outrora candente do Estado, seja no que se refere à teoria (chama a atenção, por exemplo, o bem conhecido texto de Deleuze (1992) sobre as "Sociedades de Controle", seminal para muito da reflexão política contemporânea, silenciar completamente sobre o Estado), seja no concernente à prática (a título de ilustração, tomo a liberdade de invocar uma experiência pessoal: em novembro de 2011, numa aula pública na ocupação sob o Vale do Anhangabaú em São Paulo organizada pelo movimento Ocupa

1 Pode-se ponderar que em Multidão (Hardt, Negri, 2005b), livro publicado poucos anos depois, a tese é nuançada (uma seção inclusive intitula-se "O Estado forte está de volta”); não nos parece porém haver uma mudança essencial no que concerne ao diagnóstico de época. 
Sampa, pude constatar quanto a ideia de Estado tornou-se uma espécie de besta negra, cuja ojeriza talvez só seja suplantada pela palavra "partido"). ${ }^{2}$

Pois bem, isso posto, queremos desde logo lançar uma questão, ou antes, uma suspeita. Será que as coisas se passam efetivamente como no-las pintam o correntio? Será esse cantilenado declínio do Estado algo real ou só uma espécie de ilusão de ótica política? Ponderemos. É lógico que o mero fato de haver eleições não constitui um dado determinante para demonstrar a relevância do Estado; mas por que continua sendo tão importante ganhar eleições, e portanto contar com personagens-chave nos aparatos estatais? Para não irmos além daquilo que os jornais evidenciaram nos momentos mais duros da interminável crise europeia, basta ter em mente os casos da Itália e da Grécia e dos tais "governos técnicos" que lhes foram impostos pela "troika" (Comissão Europeia, Banco Central Europeu, Fundo Monetário Internacional); 3 ou ainda o temor gerado pela vitória do socialista François Hollande nas eleições presidenciais francesas em maio de 2012 contra Nicolas Sarkozy (mesmo que todos, especialmente a grande imprensa, se apressassem em tranquilizar-nos dizendo que a capacidade de ação do recém-eleito era mínima).

Ora, se o Estado não passa de reles moribundo, por que tamanhos cuidados com quem vem ocupar a primeira cadeira? Perguntar não ofende, como ajuíza o conhecido adágio; mas tampouco é capaz de demonstrar coisa alguma. Permitamo-nos contudo, nessa interrogação, ao menos reconhecer um indício a justificar nossa suspeita: é possível que o propalado declínio do Estado não seja tão óbvio quando confrontado aos fatos. E por

2 Informações sobre o Ocupa Sampa podem ser encontradas à página: https://ocupasampa.milharal.org/. Sobre os diversos movimentos "Ocupas", ver Carneiro, 2012.

3 Sobre a noção de governo técnico, sua antiguidade e seu poder mistificatório ao santificar a separação entre técnica de governo e política, aconselhamos a leitura do artigo de Musto, 2011, que muito oportunamente retoma as considerações marxianas acerca do gabinete Aberdeen, na Inglaterra, entre dezembro de 1852 e janeiro de 1855 . 
isso arriscaremos tomar como fio condutor destas considerações um palpite, cuja razoabilidade será precisamente aquela permitida pela suspeição aduzida: longe de estar em declínio, o Estado permanece uma peça fundamental de poder, quiçá até um pouco mais que noutros tempos; um instrumento de poder que não pode ser desprezado nem sequer por seus mais renitentes inimigos (veremos como os neoliberais demonstraram saber muito bem disso). Quem sabe a aparência de redução do poderio estatal deva-se a uma verdadeira recomposição (uma esperta reformatação, para ceder um pouco ao gosto vocabular dos tempos) desse poder, com o escopo preciso de torná-lo mais apto a atuar no novo período que se abre com os inícios da globalização (a partir de meados da década de 70); e um dos elementos essenciais dessa recomposição, provavelmente o mais importante e exatamente aquele que vai aqui nos interessar, é a redefinição das relações do Estado com a ideia de segurança. A centralidade que sugerimos atribuir a esse aspecto, entre outros nada desprezíveis, não vem ao acaso. Desde o início da modernidade, e portanto desde o aparecimento mesmo dos Estados-nação, o tema da segurança esteve vinculado à própria definição de Estado bem como à determinação de seus objetivos. Restringindo-nos a dois nomes fundamentais da reflexão seiscentista sobre o Estado, é o que se lê tanto em Hobbes quanto em Espinosa: a função, logo o escopo do Estado, é garantir a "segurança" dos cidadãos; se não for para isso, ele de pouco ou de nada serve (Cf. Hobbes, 2003, pp. 143 e 1484).

O que se passa hoje? Fala-se muito, demasiado na "segurança" que é ou deve ser patrocinada pelo Estado. Mas em que sen-

4 A finalidade dos homens que se põe a viver sob um Estado é "a precaução com sua própria conservação e com uma vida mais satisfeita”, daí o soberano poder usar todos os recursos que achar conveniente "para assegurar a paz e a defesa comuns" (Cf. Hobbes, 2003, pp. 143 e 148). O escopo do Estado é "libertar o indivíduo do medo a fim de que ele viva, tanto quanto possível, em segurança" (Espinosa, 2003, p. 302). Não desconsideramos o sentido amplo da ideia de segurança entre os seiscentistas em comparação com o nosso; por ora não o discutiremos porque será isso mesmo que estará em questão neste artigo. 
tido? Tomando por base alguns estudos recentes que logo mencionaremos, é possível reconhecer uma transformação na própria concepção dessa "segurança" que a modernidade esperava do Estado, de tal modo que nossa hodierna "segurança" torne-se uma noção cujo efeito primeiro, por caminhos tortos mas não incompreensíveis, é a insegurança. Ao realizar o tradicional imperativo da segurança, uma vez que a ideia assumiu novo sentido, o Estado hoje se torna produtor de insegurança; e o faz na maior parte das vezes por redução de suas obrigações, desregulamentação, mudanças, supressão de antigos direitos. O Estado se reduz, verdadeiramente, porém (eis o ponto) isso não quer dizer menor poder, muito menos irrelevância da instituição. É possível que enxerguemos pouco Estado porque vivenciamos demasiada insegurança. De que forma menos Estado pode significar mais poder estatal? Por algum artifício o Estado tornou-se agente de insegurança, produtor de insegurança, fonte importante de poder porque administrador maior da insegurança de que o sistema (que o leitor nos permita aqui a vagueza do termo) depende.

Eis a hipótese de trabalho de que gostaríamos de partir. Uma sorte de mudança conceitual e estrutural do tema da segurança que deve ser proporcionada pelo Estado que gera a aparente diminuição do seu raio de atuação em simultaneidade com o aumento real de seu domínio. Busquemos desenvolver a hipótese em quatro passos: 1) Estado e neoliberalismo; 2) a estratégia da insegurança no início do séc. XIX; 3) a "segurança” hoje; 4) algumas considerações finais.

Segundo David Harvey, num precioso estudo sobre o assunto, o que costumamos nomear "neoliberalismo" apresentou-se, desde seus inícios, como um "projeto voltado para restaurar o poder de classe", "um projeto político de restabelecimento das condições da acumulação do capital e de restauração do poder das elites econô- 
micas" (Harvey, 2008, pp. 26-27; o quadro se enriquece bastante com a consulta a Harvey, 2009). Tudo, em suma, cuja realização topava obstáculo, maior ou menor dependendo do caso, numa espécie de "compromisso" entre classes e Estado que se delineara a partir do New Deal norte-americano, sob Roosevelt, 5 e das primeiras formulações de um Estado de bem-estar social à europeia, cuja certidão de nascimento reconhece-se no relatório sobre a segurança social de William Beveridge. ${ }^{6}$ Desse ajuizamento amplo, o que nos interessa pelo momento destacar é que tal "projeto" (de que um dos traços mais característicos é a renitente desconfiança teórica relativamente à ação estatal) só chegou a efetivar-se contando com o apoio decisivo de governos fortes, portanto sempre à mercê da tão malfadada ação estatal. Muito significativamente o primeiro experimento neoliberal, conforme a narrativa de Harvey, foi o chileno. Ou seja, as teorias da assim chamada Escola de Chicago, invariavelmente empenhadas na liberdade dos mercados, só lograram ganhar a realidade oportunamente aliadas ao porrete da ditadura de Augusto Pinochet. Depois disso somente, o mundo mais "civilizado" (com imprescindíveis aspas) conheceu o modelo de Margareth Thatcher, que embora não tenha sido exatamente ditatorial, não sem motivo mereceu o epíteto "dama de ferro".

O que entender por tal "Estado forte"? Um Estado que se fortalece na medida exata em que deixa de ser um campo de forças em conflito, internamente atravessado por relações de classe

5 O New Deal é tema bem conhecido e não vamos nisso insistir; limitamo-nos a remeter ao estudo de Limoncic, 2009, pp. 238-239, que analisa o processo sob a perspectiva das relações entre trabalho, capital e Estado, culminando em 1950, com os chamados "Acordos de Detroit", no estabelecimento de um "sistema privado de bem-estar".

6 Em plena guerra, Beveridge é chamado a presidir uma comissão encarregada de reorganizar as políticas sociais do governo britânico. Em 1942 apresenta um plano de reformas cujo princípio é o de que "o liberar-se das necessidades é uma das liberdades essenciais da humanidade”, condição a ser conquistada por um completo programa de amparo social: educação, renda mínima, saúde, aposentadoria, seguro desemprego (Cf. Beveridge, 1942; Id., 2010). Todo o ideário do bem-estar social será marcado por tais escritos, que à época angariam grande sucesso. Quanto à implantação do welfare europeu, ver Judt, 2008. 
em confronto. O ideário neoliberal, como não é segredo a ninguém, preconiza um Estado apolítico, técnico, e por isso capaz de desempenhar o papel de patrocinador imparcial e impiedoso da ordem. Ocorre que, contas feitas e por incrível que pareça, a clássica imagem do Estado-Leviatã não está tão distante dessa concepção de Estado, o qual idealmente deveria pôr-se sobre tudo, pairar sobre os antagonismos sociais dobrando-os segundo seus ditames. ${ }^{7}$ Com efeito, duas das marcas maiores do Estado neoliberal, sempre na esteira de Harvey, são: primeiro, o apreço pela administração de técnicos e uma profunda desconfiança com relação à democracia, inclusive em seus rituais mais simples (não custa lembrar o episódio de Nicolas Sarkozy e Angela Merkel indignados só pelo fato de os gregos, à iminência da bancarrota, terem ousado cogitar um referendo acerca de certas mudanças de rumo na Grécia) ${ }^{8}$; em segundo lugar, um inegociável privilégio do judiciário na balança montesquiana dos três poderes, já que "o conflito e a oposição devem ser mediados pelos tribunais" e "soluções e remédios para todo e qualquer problema devem ser buscados por meio do sistema legal” (Harvey, 2008, p. 77). ${ }^{9}$ É por conta desses dois traços essenciais que o Estado neoliberal almeja funcionar, se não como o agente (termo que horrorizaria os neoliberais) decerto como o fiador de uma acumulação de capital desentravada. No mais recente $\mathrm{O}$ enigma do capital, que analisa a crise das hipotecas nos EUA, Harvey é insistente ao defender a

7 Uma vez que atrás mencionamos Deleuze, justiça seja agora feita com a remissão a algumas linhas muito precisas em que ele e Guattari estabelecem o nexo fundamental aqui em foco: "o Estado totalitário não é um máximo de Estado, mas antes [...] o Estado mínimo do anarcocapitalismo (cf. Chile)" (Deleuze, Guattari, 2012, p. 176). Quanto à problemática do Estado nesses autores, fica o reenvio ao instigante estudo de Sibertin-Blanc, 2013, que infelizmente não consideramos ao preparar este texto.

8 Cf. "Sarkozy e Merkel advertem que referendo grego influenciará manutenção na Zona Euro", 3 de novembro de 2011, disponível em: http://pt.euronews. com/2011/11/03/sarkozy-e-merkel-advertem-que-referendo-grego-influenciara-manutencao-na-zona-/ Trata-se de uma única indicação; notícias similares se podem encontrar aos montes com uma simples busca na internet.

9 Observe-se que muito da hoje denunciada "criminalização dos movimentos sociais" deve-se a isso. 
tese de que não existe financeirização da economia sem Estado; em especial na ausência de um Estado apto a torná-la um fato; como ele conclui, o "nexo entre o Estado e as finanças há muito tempo funciona como 'sistema nervoso central' da acumulação capitalista" (Harvey, 2011, p. 69).

Visto isso, inevitável perguntar: poderá dito Estado ser qualificado de "fraco"? O Estado "mínimo" dos neoliberais pode simplesmente ser considerado uma instituição em declínio? É razoável desconfiar que não. Pelo contrário, tomadas as coisas sob um ângulo que não seja o do senso comum ou quem sabe do senso interesseiro, trata-se de um Estado cuja pretensa e aparente fraqueza constitui uma força secreta. A sua alegada debilidade é antes a mistificação de uma fonte incomparável de poder, já que lhe permite, com mão de ferro, impor goela abaixo de toda gente os imperativos do mercado e da acumulação de capital bem como o poder de classe. É a aparência de capenga que lhe faculta desatrelar-se dos impedimentos advindos do social, pairar sobre a sociedade e no limite destruí-la, mediante ditaduras e também no plano das ideias (impossível não recordar aqui Thatcher: "a sociedade não existe, apenas homens e mulheres individuais; e há famílias"; apud Harvey, 2008, p. 92).

O mecanismo privilegiado dessa operação é a limitação de qualquer poder proveniente do social, portanto o controle rígido da sociedade; o que por sua vez se consegue, queremos crer, com um expediente muito preciso cuja análise aqui nos toca: a redefinição, e aplicação ampla dessa redefinição, da ideia tradicional de segurança cuja incumbência seria do Estado. Não que se trate de um artifício inteiramente novo, mas é que no período dito neoliberal, isto é, a partir de meados dos anos 70, assume tonalidades, meios e justificativas renovadas. A fim de percebê-lo, vale a pena retroceder um pouco no tempo, para na sequência reatarmos o fio da contemporaneidade. 
Foucault, na segunda aula de seu curso sobre o Nascimento da biopolítica, ao analisar o imbricamento entre o liberalismo e uma nova arte de governar que vai tomando forma na virada do XVIII para o XIX, chama-nos a atenção para um processo determinante (e para nós deveras esclarecedor): a ascensão da categoria "mercado", teórica e praticamente, é simultânea ao imperativo de limitar a potência pública. "Não se podia pensar a economia política, isto é, a liberdade do mercado, sem pôr ao mesmo tempo o problema do direito público, ou seja, a limitação da potência pública" (Foucault, 2004, p. 40). Eis que uma ciência, uma teoria não pode ser concebida senão sob o amparo de um ato de força prática; um pouco como, pelo que vimos em Harvey, as obsessões teóricas dos garotos de Chicago precisaram inicialmente, em benefício de sua própria pensabilidade, da colaboração ativa de Pinochet.

Essa "limitação da potência pública" identificada por Foucault não era fato invisível aos homens da época. O jovem Marx percebera movimentação semelhante, como se depreende de um texto de 1844. A economia política inglesa, explica ele, compreende o pauperismo que então se alastrava como uma particularidade da legislação inglesa tradicional sobre os pobres, a qual seria excessivamente benévola com os miseráveis. Na medida em que obrigava as paróquias a prover auxílio aos necessitados e permitia a cobrança de impostos para tanto, tal legislação não faria senão gerar mais pobreza, pois os pobres ficariam desobrigados dos cuidados com seus próprios interesses, em especial o de superar a sua condição miserável (nos termos de certos debates brasileiros atuais, o problema estaria no descuido relativamente ao que se costuma denominar "porta de saída"). Daí, arremata Marx, a ocasião de uma nova lei dos pobres no ano de 1834, em perfeita coincidência com um momento de intensa ascensão do capitalismo inglês e que servisse para equacionar a existência dos pobres (da qual de maneira alguma se podia abrir mão) e novas exigências econômicas e políticas. 
O pauperismo foi tomando a forma de uma instituição nacional $[$...] tornando-se [...] objeto de uma administração ramificada e bastante ampla, uma administração que, todavia, não possui mais a incumbência de sufocá-lo, mas de discipliná-lo, de perpetuá-lo. [...] O Estado inglês, longe de ir além das medidas administrativas e beneficentes, retrocedeu aquém delas. Ele se restringe a administrar aquele pauperismo que, de tão desesperado, deixa-se apanhar e jogar na prisão (Marx, 2010, p. 35).

Tudo naturalmente feito, como autoriza e recomenda o breviário da luta de classes, com a preciosa "benevolência policial", responsável por dissuadir os espíritos mais renitentes.

O que podemos apreender dessas considerações não é pouco. Um Estado, mediante o uso da legislação, é capaz de restringir a potência pública, discipliná-la, e o faz com precisão e grande senso de oportunidade, na ocasião devida - para ficarmos só no caso da nova legislação inglesa mencionada, impossível esquecer que ela surge exatamente num momento em que pobres e trabalhadores começam a questionar sua situação e dão os primeiros passos rumo à organização de suas reivindicações; a década de 1830 marca o início do movimento cartista e a nova lei dista só 8 anos daquela que será, aos olhos Friedrich Engels, a primeira demonstração de força do proletariado inglês: a greve de 1842, por ele denominada "insurreição", que para a região algodoeira de Manchester (cf. Engels, 2010, principalmente o capítulo "Os movimentos operários"; para uma análise dos eventos de 1842, ver Marcus, 1980). E não só isso. Imprescindível salientar ainda a peculiaridade do artifício legislativo em questão: sua eficácia provém não tanto do que faz quanto do que impede de continuar sendo feito. A limitação do social identificada por Foucault e tão bem ilustrada por Marx dá-se, entre outras formas possíveis, pela produção da insegurança conseguida graças à desincumbência de obrigações para com os pobres que o Estado inglês assumira havia séculos, processo que tem esteio numa determinante recompre- 
ensão da própria essência da pobreza. Ao medo permanente da fome acrescenta-se a perseguição e a mácula social; a pobreza tornada crime, passível de punição, prisão ou internamento nas famigeradas workhouses (que tinham fama tão ruim que era preferível qualquer trabalho miserável ao recolhimento compulsório, como nos relatam Engels, 2010, p. 318 e Marcus, 1980, pp. 17-18).

Relativamente a nosso assunto, está aí um expediente a ser bem discernido. Ao desincumbir-se de suas obrigações seculares para com os pobres, e assim atuar menos, o Estado efetua um ato de força pelo qual possibilita a ascensão e estabelecimento do mercado mediante um novo tipo de administração, e portanto atuando mais e abrindo uma nova frente de ação: a administração dos pobres. Pode parecer paradoxal, mas não. A desregulação (não se obriga ninguém a pagar impostos para custear obras de caridade) é uma forma precisa de controle que visa regulamentar, por outras vias, a massa trabalhadora (o "material humano", diriam alguns) que tem de estar disponível para a relação assalariada ao invés de, como se apregoava, ficar vagabundeando a expensas da caixa paroquial.

Feito esse excurso, voltemos ao núcleo de nossa hipótese. Cabe indagar, antes de tudo, se não seria esse processo que acabamos de avistar no século XIX semelhante àquele que conhecemos pelo menos desde os anos 80 do XX. O Estado fraco do liberalismo inglês "clássico" não se parece em algo com o Estado fraco de nossos dias? ${ }^{\circ 0}$ Como aquele solidificou as bases da acumulação, não serviu este a restaurar suas condições de possibilidade?" Ainda

10 O adjetivo "clássico" é a entender-se no sentido que lhe reservam Engels e Marx ao falar da Inglaterra do período; cf. Engels, 2010, pp. 41, 45; Marx, 1983, p. 12. No mais, ainda aqui são pertinentes as considerações marxianas analisadas por Musto, 2011.

11 Engels notava que, apesar de o Estado aparecer como um "estorvo" ao burguês, cujo "ideal seria operar numa ordem social privada de Estado", ele "não pode dispensar o Estado" (Engels, 2010, p. 309). São as mesmas contradições que Harvey detecta no neoliberal. 
que não tratemos de processos idênticos, cremos plausível identificar uma convergência. Mutatis mutandis, em ambos os casos a diminuição do Estado, particularmente a desincumbência de certos encargos que eram de sua alçada, constitui uma política de produção de insegurança que se presta ao enfraquecimento do social ou pelo menos de parcela importante dele; ou pela própria organização estatal, ou sob a anuência do Estado, toma forma um poder que se exerce, não só mas prioritariamente, pela insegurança e disseminação do medo. Por isso mesmo, nos dois casos, a redução da ação estatal, a ampliação dos setores em que o Estado não deve intervir é a ser lida como signo de seu fortalecimento, de um ganho de autonomia, que simultaneamente o liberta das amarras e pressões sociais e produz, no plano das aparências, a impressão de sua debilidade, até mesmo de seu declínio.

Não haverá maneira mais esclarecedora de captar algo da natureza desse processo - paradoxal só na aparência - que pela temática tradicional da "segurança", aquela mesma que, reitere-se, desde a abertura da modernidade esteve firmemente vinculada ao estabelecimento dos Estados-nação. Pois esse fortalecimento do Estado se alcança por uma decisiva transformação da ideia; novas determinações, deslocamentos de sentido, por assim dizer, que quadram todos à diminuição da potência social e simultâneo aumento da potência dominante, na medida em que fazem da "segurança" produtora certeira de "insegurança". Repassar brevemente três dessas redeterminações bastará para conduzir-nos ao ponto que pretendemos alcançar.

\section{Segurança jurídica}

Qual justificativa poderia ter, na história das relações entre justiça e segurança, a ideia de uma segurança jurídica? Sumariamente, proteger os cidadãos da arbitrariedade das autoridades instituídas, garantir-lhe acesso à justiça e aos direitos previstos, permitindo assim o conflito político dentro de certos limites, para lá dos quais só valeria a lei do mais poderoso. É o que se depreen- 
de da arguta análise que Claude Lefort faz das críticas marxianas, n’A questão judaica, à "Declaração dos direitos do homem e do cidadão". Não está lá apenas o apanágio de uma nova sociedade, como também uma conquista, ambígua mas certamente uma conquista, do que podemos designar alguns dos constituintes essenciais da noção de segurança jurídica. A mera afirmação de que todo homem é inocente até prova em contrário, por exemplo, já "supõe que há inocentes, culpados e terceiros, suscetíveis de confundir arbitrariamente uns e outros ou de saber distingui-los". Destarte, a declaração promove de maneira decisiva um inédito "desintricamento do poder e de direito" (Lefort, 1987, pp. 54-55).

Aqui, novamente, o recurso à história do neoliberalismo de David Harvey é elucidativo. O marco de uma verdadeira ressignificação da ideia de segurança jurídica pode-se localizar na crise fiscal da cidade de Nova York nos anos 70. O governo municipal já vinha enfrentando graves complicações financeiras desde a década anterior por conta dos gastos e dos empréstimos assumidos. Tudo é piorado pelo cenário de crise mundial e, principalmente, no começo da década de 70, pela decisão do presidente Richard Nixon de reduzir drasticamente a ajuda federal aos programas do município que atendiam populações excluídas. Em 1975 os banqueiros recusam-se a rolar a dívida da cidade e ela simplesmente vai à bancarrota. Para o salvamento das finanças nova-iorquinas, a contrapartida exigida, embora cara, logo é alcançada: a "total liberdade de gestão das receitas de impostos a fim de pagar em primeiro lugar os acionistas, ficando o que restasse para ser empregado em serviços essenciais". Um "golpe", conclui Harvey (Harvey, 2008, pp. 54-55), contra o governo eleito da cidade. Ato de força bruta similar ao chileno, se não na forma ao menos nos efeitos, a patentear que doravante, entre os contratos e as populações, assegurados devem ser os primeiros, depois, só depois e se possível, as segundas. "Segurança jurídica", a partir de então, assume um significado claro por sua contundência, isto é, insegurança para as populações, para os cidadãos. 


\section{Segurança social}

Uma transformação semelhante à anterior é detectável no que podemos denominar, de forma genérica, "segurança social". A ideia de que há direitos essenciais como educação, saúde, aposentadoria, alimentação, etc., conheceu um longo período de formação e impôs-se aos poucos como resultado de aguerridos conflitos sociais; fato é que, ao fim e ao cabo, logrou uma inflexão fundamental na maneira de se conceberem os objetivos do Estado, especialmente a partir de meados do século XX: mesmo Estados que não satisfaziam tais direitos, ao menos no plano de sua legitimação não podiam simplesmente renegá-los. Ora, o que descobrimos nos dias que correm? A segurança social, portanto da alçada da sociedade, vê-se aos poucos substituída pela ideia de segurança individual, de inteira responsabilidade do indivíduo, ao qual cabe garanti-la pela conquista (a imagem bélica é apropriada) de um bom emprego, com boa renda, graças a seus esforços pessoais, sua dedicação e competência no trabalho, sua eficácia no planejamento das coisas da vida. Pior, como efeito dessa situação, a conduta eficaz daquele que é capaz de assegurar-se por conta própria delimita reversamente o campo dos não-enquadrados, os ineficientes, irresponsáveis, que merecem ser punidos com a insegurança - um pouco, ainda aqui, como à época de Marx. Num interessante estudo de Loïc Wacquant (2006), justamente intitulado Punir os pobres, o quadro é amplamente analisado. Segundo o autor, um dos paradigmas dessa estratégia de penalização pode ser identificado na "Lei sobre a responsabilidade e o trabalho", aprovada em 1996 nos EUA sob o governo Bill Clinton, que visava economizar bilhões de dólares mediante o corte de benefícios à infância, a idosos e mães solteiras. É suficiente um trecho para elucidarmos o que está em jogo:

Como pode uma sociedade em que, em 1995, uma mãe em cada duas e uma criança em cada cinco [...] viviam abaixo da linha oficial de pobreza continuar convencida que a miséria que atinge tantos dos seus membros 
mais vulneráveis seja consequência de suas falhas individuais? [No caso a maternidade fora do casamento]. A resposta a essa interrogação deve ser buscada na radicalização da ideologia estadunidense da família, da infância e da maternidade que faz das mães sem maridos (e dos filhos sem pai) seres anormais, incompletos, suspeitos, que ameaçam a ordem moral e sobre os quais o Estado deve exercer um severo controle. (Wacquant, 2006, p. 96; interpolação nossa)

Assim é que grandes parcelas da população são marginalizadas, isto é, postas em situação de aguda insegurança, relegadas à própria sorte, sem auxílios, inculpadas pela própria miséria. (À semelhança de uma imagem, um dado também é capaz de valer por mil explicações: em meados da década de 8o, volta-se a falar seriamente em "desemprego voluntário", noção que parecia sepultada desde a abertura da Teoria geral de Keynes. ${ }^{12}$ )

\section{Segurança pública}

Atualmente, no que concerne ao termo "segurança", nenhuma associação é tão imediata quanto aquela que a vincula ao criminalidade e da necessária defesa, contra ela, da parte das "pessoas de bem"; a tal ponto que todo o campo semântico da palavra parece hoje poder ser recoberto por tal questão. A “segurança pública” e a ordem que ela visa garantir tornam-se, em última instância, assunto de polícia. Significativa restrição que faz da segurança, que se punha noutros tempos como escopo estatal à maneira de garantia de uma vida cômoda, das condições para o livre desenvolvimento das potencialidades, um objeto de política policial; o que, por sua vez, torna a polícia um instrumento de política pública. Ou antes a devolve a tal posto; pois como vimos Marx constatar em 1844 relativamente à nova lei dos pobres, para

12 Ver a análise da "teoria clássica do emprego" e a avaliação que se segue no cap. 2: "Os postulados da economia clássica”, de Keynes, 1983. 
funcionar ela precisa contar com a "benevolência da polícia"; afinal é esta que lá na ponta tem de efetivar o que se decide nos palácios.

Sob essa perspectiva, não espanta que a própria noção de "ordem pública" possa revelar-se, tão amiúde, produção organizada de intranquilidade e insegurança para parcelas marginalizadas da população; uma política de Estado (e foi o caso da notória política de "tolerância zero", admirada mundo afora e não fortuitamente nascida numa Nova York posta de joelhos por banqueiros) que enfraquece o social pelo amedrontamento, pela criminalização dos questionamentos mais incisivos (assimilados a "desordens" inaceitáveis), não poucas vezes por um processo de encarceramento em massa. A respeito deste último ponto, aliás, o mesmo Loïc Wacquant há pouco invocado trata longamente daquilo que, na esteira de Foucault, chama de "grande confinamento"; fenômeno que a seu ver marca o final do século XX e dá forma a um "Estado penal" cujos cidadãos são pobres, pretos, árabes, imigrantes, toda a sorte de "escória" (expressão, não custa lembrar, que o então presidente Sarkozy utilizou em 2005 para designar os jovens revoltosos da periferia parisiense, em sua maioria filhos de imigrantes).

Vão aí apenas algumas indicações que não pretendem esgotar o tema de uma nova "segurança", seus diversos sentidos e seus efeitos determinados na produção de "insegurança"; muitos desdobramentos ainda seriam possíveis, a abordagem de outros aspectos, sobretudo como se chegou ao ponto de razões de Estado poderem sacrificar liberdades em nome justamente da segurança. De qualquer modo, parecem-nos dar conta de balizar três considerações que já foram mais ou menos afloradas e que devem justificar a ideia de que o Estado, longe de ter-se tornado ente irrelevante, ainda hoje é instituição de enorme importância e que merece nossos cuidados, práticos e sobretudo teóricos:

1ª) Pelo prisma do par segurança/insegurança delimita-se uma renovada forma (de raízes antigas, mas ainda assim renova- 
da) de poder, cujo exercício se dá sobretudo pelo aparato estatal. Esse controle é capaz (e que nos seja permitido aqui saudar mais uma vez Espinosa) de dominar não apenas corpos como também almas, manipulando com argúcia alguns afetos que são naturalmente nossos, especialmente medo e esperança. ${ }^{13}$

$2^{a}$ ) Dito exercício de poder ocorre privilegiadamente na esfera estatal, e de maneira muito peculiar por subtração; o que tem como decorrência o aparente enfraquecimento do Estado e do poder mesmo que é o seu - e nisso reside toda a esperteza do expediente. Por exemplo, a supressão de um direito trabalhista parece fraqueza, pois o Estado se teria dobrado a interesses de empregadores (ora, para que serve se não consegue nem mesmo manter um direito? só pode estar em declínio); contudo, revela-se aí a força do Estado como instrumento de poder daqueles que o comandam e conseguem impingir, por meio dele, seus propósitos. Estamos no registro da regra de três, onde menos vale mais. A instituição não se enfraquece, fortifica-se, inversamente, na proporção mesma em que enfraquece a sociedade.

3a) Mediante uma reinterpretação do imperativo estatal da segurança, pode-se estabelecer a produção sistemática de insegurança, disseminação e organização do medo (de ficar desempregado e sem amparo financeiro, de adoecer sem acesso à saúde, de não ter como pagar uma escola razoável aos filhos, etc.). Não se trata exatamente de administrar a pobreza, mas de enfraquecer a sociedade para controlá-la, torná-la disponível, dócil aos mandamentos da acumulação capitalista; por meio do expediente da "insegurança”, produzir a precariedade em larga escala, de corpo

13 "Tem um outro sob o seu poder quem o detém amarrado, ou quem lhe tirou as armas e os meios de se defender ou de se evadir, quem lhe incutiu medo ou quem, mediante um benefício, o vinculou de tal maneira a si que ele prefere fazer-lhe a vontade a fazer a sua. Quem tem um outro em seu poder sob a primeira ou a segunda destas formas, detém só o corpo dele, não a mente; mas quem o tem sob a terceira ou a quarta forma fez juridicamente seus, tanto a mente como o corpo dele, embora só enquanto dura o medo ou a esperança; na verdade, desaparecida esta ou aquele, o outro fica sob jurisdição de si próprio.” (Espinosa, 2009, cap. II, \10) 
e principalmente de espírito. ${ }^{14}$ Processo de enfraquecimento do social e simultâneo aumento do poder do Estado e dos dominantes. Daí, assim como tanto se fala em acumulação do capital, ser necessário também falar em acumulação de poder, e perceber que o Estado ainda é o lugar privilegiado para o exercício dessa atividade.

Na contramão dos diagnósticos de irreversível declínio da instituição estatal ou de sua pura e simples irrelevância, Harvey (Harvey, 2011, pp. 276-277) arremata sua análise da crise norte-america concluindo ser impossível, ainda hoje, efetivar-se uma nova ordem sem contar com o poder dos Estados. Será acertado esse ajuizamento? Nos limites que nos traçamos, seria demasiado avançar uma resposta. Contudo, pensamos que dentro desses mesmos limites e lastreados no trajeto feito, ao menos um dado pode ser bem estabelecido: o erro contido no desinteresse pelo

14 Numa análise notável em que compara a situação dos camponeses alemães e a dos proletários ingleses e acerta o alvo como nunca, Engels detectou a causa principal da proletarização nas condições de vida disseminadas pela produção capitalista inglesa: absoluta despossessão, completa incerteza quanto ao futuro mais imediato, império do acaso, inteira disponibilidade à exploração. "A insegurança de sua vida, a necessidade de viver cada dia com um salário sem saber o que lhe acontecerá na manhã seguinte - em suma, aquilo que faz deles proletários"; (Engels, 2010, p. 155; grifo nosso). Nenhuma das analogias possíveis entre a situação do proletariado inglês e a do nosso "precariado" deve ser considerada casual. A precariedade atual (cujos contornos são mais e mais esmiuçados por uma literatura que não para de crescer) não seria novo desdobramento de um traço essencial do domínio capitalista (a promoção da insegurança)? Os meios são novos, evidentemente, porém a disponibilidade a qualquer coisa e a inteira mercê ao acaso acarretadas por condições hoje rotineiras como o endividamento (cf. Lazzarato, 2012) ou a fragilidade e a auto-inculpação trazidas pela depressão laboral (cf. Pereira, 2011) seguem muito úteis ao controle social. Ora, se assim for, dir-se-á que nosso tempo acaba por se mostrar mais "clássico" que o período do Estado de bem-estar nos países centrais, quando a acumulação capitalista dependia de um uso arrazoado, e por isso encontrava-se um pouco amarrada, pela ideia de segurança. (A título de exemplo e em claríssimo contraste com a mencionada lei norte-americana "sobre a responsabilidade e o trabalho", ver o estudo de Dalla Costa, 1997, que mostra como a legislação newdealista de proteção familiar servia aos interesses capitalistas de reprodução de mão de obra apropriada às suas necessidades de então.) 
tema do Estado; atitude não raro demonstrada por muitos dentre os que se preocupam com a transformação do presente ordenamento de coisas.

Miremos o caso dos neoliberais, que por volta dos anos $60 / 70$ estavam realmente empenhados em alterar o rumo das coisas. É flagrante que dessa falha teórica não podem ser acusados, pois que sempre reconheceram, não obstante as aparências, a posição-chave do Estado para a efetivação de qualquer mudança importante. Fora o Estado que a partir de meados do século XX impusera certos freios à livre atuação do capital, ou melhor, sob pressão do social (embates variados, greves, ameaças de revolução que se gestavam por toda parte) fora ele tornado um instrumento importante para tal efeito. Ora, o neoliberal arguto bem se apercebeu disso e daí seu "projeto" de restauração das condições ótimas de acumulação jamais ter deixado de incluir uma séria reflexão sobre o Estado e os meios mais adequados de usá-lo em acordo com seus intentos. Imunes às preocupações transcendentais que costumam obsedar os filósofos (definições, meios de fundamentação e legitimação), os neoliberais estavam livres para considerar a instituição estatal sob o prisma das práticas e dos efeitos, indagar como moldá-los a fim de contribuir com seus propósitos; em suma, serem úteis ao seu programa transformador. ${ }^{15}$

Algo desse modo de pensar o Estado bem que nos pode inspirar a reflexão.

Antes de tudo, resistir à tentação de essencializá-lo; afastar a ideia de que seja essencialmente mau, não ceder à fantasia de que seja essencialmente bom; nem encarnação terrena do racional

15 No citado curso sobre o Nascimento da biopolítica, Foucault contrapõe dois modos de considerar o Estado e suas ações. Um primeiro, filosófico; outro, o da economia política, que toma o objeto "do lado de seus efeitos", quer dizer, em vez de uma "objeção externa à razão de Estado" (tal ação é legítima? justa? bem fundada?) trata-se de permanecer no "campo da prática governamental" e perguntar pela utilidade ou inutilidade das ações (Foucault, 2004, Pp. 16-17). Um estudo aprofundado desse ponto encontra-se em De Lagasnerie, 2013. 
nem figuração da barbárie. O Estado-Leviatã tanto quanto o Estado-Providência revelam-se imagens pobres, incapazes de exprimir todas as facetas e ambiguidades do retratado. Pior, no âmbito da prática, essas alternativas solidárias conduzem frequentemente a posições extremas: à perfeita submissão, ou porque o poder estatal seja efetivamente bom ou porque seja invencível; à rejeição em bloco, ou por ser o Estado efetivamente mau ou por não passar de um QG de classe dominante que não merece senão a destruição. Nada disso. Como toda instituição humana, o Estado é ambíguo. E importante é restituir-lhe à ambiguidade, repondo-o como lugar sempre permeável a disputas, pressões, tensões, embates de classes, grupos, indivíduos, que podem conduzi-lo para lá e para cá em benefício de seus intentos. Se o Estado é um dos campos privilegiados de acumulação do poder, não haveria por que abrir mão desse importante instrumento de transformação social. Em suma, para lá da aparência de irrelevância, é necessário pôr a questão adequada: para que serve? qual sua utilidade?, sabendo usá-lo, se for o caso, sem pejos nem ilusões.

Eis um desafio premente que se deve impor sobre o senso difuso de declínio do Estado: retomá-lo como tema; reaprender a considerá-lo; repensá-lo em novos termos. ${ }^{16}$ Como? Queremos crer que uma via promissora é analisar o Estado (sua relevância, sua utilidade, seu poder) pelo prisma do par segurança/insegurança. Primeiramente, com isso não nos afastamos da própria tradição moderna que, qual já observado, concebe a instituição estatal como se justificando prioritariamente pela promoção da segurança, e portanto à guisa de promotor das bases para uma vida

16 É justo observar que o historiador Tony Judt (2011), estipula a mesma tarefa (repensar o Estado) e ressalta sua urgência. Trata-se de um livro instigante, entre outros aspectos, especialmente por sua leitura política do neoliberalismo e compreensão de como o aspecto crucial dessa corrente desenvolveu-se menos no plano econômico que na reelaboração de nossas concepções de Estado; os pontos fracos (por exemplo, pouco se pergunta quanto o welfare europeu dependeu do neocolonialismo) não comprometem as teses de conjunto nem os problemas em geral bem colocados. É uma pena que a obra não tenha fomentado, ao menos entre nós, as discussões que propunha. 
boa e livre. Segundo, permite não continuarmos reféns da velha tentação de mera tomada do aparato estatal e não temer o jogo das alternâncias de cadeiras, pensando antes em termos de correlação de forças antagônicas que atravessam o social e para as quais o Estado, embora objeto de disputa extremamente relevante, jamais constitui o fim último. Por fim, guarda-nos da primazia do ponto de vista das razões de Estado, dependente das ilusões gêmeas do Leviatã e da Providência, ao conceber o bom equacionamento de poder entre o aparato estatal e o social, já que o enfraquecimento de um é o fortalecimento de outro e vice-versa.

Tornemos ao já visto. Por estreitamento de seu raio de ação, por desincumbência de funções, o Estado neoliberal torna-se um agente produtor de insegurança. $\mathrm{O}$ inimigo aí visado, se podemos assim dizer, não seria tanto o próprio Estado quanto uma sociedade que por suas pressões dele fizera empecilho à livre acumulação do capital. Daí porque, prática e teoricamente (Pinochet e Thatcher), o social precisa ser dobrado, e a estratégia é a acumulação de poder no próprio Estado, uma vez que o fortalecimento deste implica o simultâneo enfraquecimento daquele (não obstante a impressão de que a realidade seja outra). Pois o que nos caberia, hoje, é repensar o Estado no interior dessa mesma lógica. Ou seja, reafirmar (teórica e praticamente) a segurança como tarefa do Estado, justificativa de sua própria existência, já que só assim se torna útil à sociedade, e dar-lhe meios para realizar tal utilidade. Em especial, cumpre conceber a segurança como requisito da liberdade, no reverso do Estado de insegurança sobre que insistimos e que configura a nossa situação. Desde que não acatemos o amesquinhamento da noção, a segurança (e particularmente aquela que pode ser propiciada pelo Estado em termos de transporte, saúde, educação, e tudo mais que se puder inventar) é condição sine qua non de uma sociedade livre. ${ }^{17}$ 
É provável que a ideia cause espécie a alguns. Fortalecer o Estado!? Nutrir o Leviatã!? Tais brados, contudo, não nos devem afrouxar a guarda. Só uma visão unilateral e empobrecida do Estado pode assim equacionar as coisas; ademais, o fortalecimento do Estado exigido para a ampla garantia da segurança é só uma aparência, como o é a noção corrente de seu enfraquecimento quando se faz agente de insegurança. Usar tal instituição como instrumento para promover a segurança e fazê-lo de tal modo que seu aparente fortalecimento implique o seu real enfraquecimento como aparato autônomo ou disponível a grupos de interesse, é produzir, isto sim, o real fortalecimento do social, que liberto da precariedade e do medo paralisante, da insegurança em suma, possa florescer para a liberdade. Sem tomada de poder, sem perpétuos assentos em sua máquina, sem perspectiva de destruição. Nada mais (e também nada menos) que aquilo que um Marx, nesse assunto, estipulara como tarefa crucial: subordinar o Estado à sociedade. ${ }^{18}$

O Estado, ao proporcionar segurança, não dá a boa vida. Pode garantir um horizonte, condições de possibilidade da boa vida que desabrocha conforme a nossa natureza. Isto é que interessa pensar com relação ao Estado: suas responsabilidades, sua atuação, seus efeitos como agente de segurança. É um instrumento. Para tanto, não temos nem de fantasiá-lo nem de depreciá-lo, apenas redescobrir seu caráter (este sim essencial) ambíguo. É atitude que está longe de tudo tomar pelo ponto de vista do Estado (fazer das tripas coração para lá permanecer, bater contra os movimentos por razões de Estado, e assim por diante). O ponto

nem subjugar os homens pelo medo e submetê-los a um direito alheio; é, pelo contrário, libertar o indivíduo do medo a fim de que mantenha da melhor maneira, sem prejuízo para si ou para os outros, o seu direito natural a existir e a agir."

18 "A liberdade consiste em converter o Estado, de órgão que subordina a sociedade em órgão totalmente subordinado a ela” (Marx, 2012, p. 42). Por conseguinte, a tradicional ênfase dada, nessas páginas, à ideia de uma "ditadura do proletariado" (cf. Lênin, 1980, p. 280 seg.) é a ser descartada. 
de vista que importa é o da sociedade, não a fantasiada, una, alegre e harmônica, porém a real, que se expressa nas lutas sociais e que pode fazer o Estado pender para cá e para lá, conduzindo-o, manipulando-o, como fazemos com qualquer utensílio. O Estado não é a única instituição apta a isso, evidentemente; entretanto, ainda consiste numa instituição fundamental para a promoção da segurança da sociedade, num sentido forte e que não pode ausentar-se da reflexão política sequer um minuto. Daí a tarefa que se impõe hoje, nesse âmbito, ser mormente teórica. Como a teoria do Estado mínimo teve de ser elaborada para tornar possível sua efetivação, a teoria da segurança, isto é, de uma sociedade forte, requer igualmente nossos esforços, pois só assim poderá encontrar, não no porrete de Pinochet mas na sociedade, o necessário apoio para sua efetivação.

Referências bibliográficas

BEVERIDGE, W. 1942. Social Insurance and Allied Services, Reported by Sir William Beveridge. Londres: His Majesty's Stationery Office, 1942. Disponível em: <http://news.bbc. co.uk/2/shared/bsp/hi/pdfs/19_07_05_beveridge.pdf>. Acesso em: 4 nov. 2015 . . La libertà solidale. Scritti 1942-1945. Michele Colucci (org.). Roma: Donzelli Editore, 2010.

CARNEIRO, H. S. "Rebeliões e ocupações de 2011”. In: Occupy.

Movimentos de protesto que tomaram as ruas. São Paulo: Boitempo, Carta Maior, 2012.

DALLA COSTA, M. Famiglia, welfare e stato tra progressismo e

New Deal. Milão: Franco Angeli, 1997.

DE LAGASNERIE, G. A última lição de Foucault. Sobre o neoliberalismo, a teoria e a prática. Trad. André Telles. São Paulo: Três Estrelas, 2013.

DELEUZE, G. "Pós-escrito sobre Sociedades de Controle". In: 
DELEUZE, G. Conversações. Trad. Peter Pál Pelbart. Rio de Janeiro: Ed. 34, 1992.

; GUATTARI, F. Mil platôs, vol. 5. Trad. Peter Pál Pelbart e Janice Caiafa. São Paulo: Ed. 34, 2012.

ENGELS, F. A situação da classe trabalhadora na Inglaterra. Trad. B. A. Schumann. São Paulo: Boitempo, 2010.

ESPINOSA, B. Tratado teológico-político. Trad. Diogo Pires Aurélio. São Paulo: Martins Fontes, 2003. Tratado político. Trad. Diogo Pires Aurélio. São Paulo: WMF Martins Fontes, 2009..

FOUCAULT, M. Naissance de la biopolitique. Paris: Gallimard, Seuil, 2004.

HARDT, M; NEGRI, A. Império. Trad. Berilo Vargas. Rio de Janeiro: Record, 2005 a. Multidão. Guerra e democracia na era do Império. Trad. Clóvis Marques. Rio de Janeiro: Record, 2005b.

HARVEY, D. O neoliberalismo. História e implicações. Trad. Adail Sobral e Maria Stela Gonçalves. São Paulo: Loyola, 2008. Condição pós-moderna. Trad. Adail Ubirajara Sobral. São Paulo, Loyola, 2009 .

O enigma do capital e as crises do capitalismo. Trad. Maria Carvalho. Lisboa: Bizâncio, 2011.

HOBBES, T. Leviatã. Trad. João Paulo Monteiro e Maria Beatriz Nizza da Silva. São Paulo: Martins Fontes, 2003.

JUDT, T. Pós-guerra. Uma história da Europa desde 1945. Trad. José Roberto O’Shea. Rio de Janeiro: Objetiva, 2008.

O mal ronda a terra. Um tratado sobre as insatisfações do presente. Trad. Celso Nogueira. Rio de Janeiro: Objetiva, 2011.

KEYNES, J. M. Teoria geral do emprego, do juro e do dinheiro. Trad. Mário R. da Cruz. São Paulo: Abril Cultural, 1983.

LAZZARATO, M. La fabbrica dell'uomo indebitato: Saggio sulla condizione neoliberista. Roma: Derive Approdi, 2012.

LEFORT, C. "Direitos do homem e política”. In: LEFORT, C. A 
invenção democrática. Os limites do totalitarismo. Trad. Isabel Marva Loureiro. São Paulo: Brasiliense, 1987.

LÊNIN, V. I. O Estado e a revolução: a doutrina do marxismo sobre o Estado e as tarefas do proletariado na revolução. In: LÊNIN, V. I. Obras escolhidas, vol. 2. Vários tradutores. São Paulo: Alfa-ômega, 1980.

LIMONC, F. Os inventores do New Deal. Estado e sindicatos no combate à Gande Depressão. Rio de Janeiro: Civilização Brasileira, 2009.

MARCUS, S. Engels, Manchester e la classe lavoratrice. Trad. Luca Fontana. Turim: Einaudi, 1980.

MARX, K. O Capital: Crítica da economia política, vol. I. Trad. Regis Barbosa e Flávio Kothe. São Paulo: Abril Cultural, 1983. . "Glosas críticas ao artigo 'O rei da Prússia e a reforma social'. In: ENGELS, Friedrich; MARX, Karl. Lutas de classes na Alemanha. Trad. Nélio Schneider. São Paulo: Boitempo, 2010.

. Crítica do programa de Gotha. Trad. Rubens Enderle. São Paulo: Boitempo, 2012.

MUSTO, M. "Grécia, Itália e os sagazes sarcasmos de Marx sobre os “governos técnicos"'. Carta Maior, 2011. Disponível em: $<$ http://www.cartamaior.com.br/templates/materiaMostrar. cfm?materia_id=18956>. Acesso em: 4 nov. 2015.

NEGRI, A. Crisi dello Stato-piano (1 $1^{\mathrm{a}}$ ed. 1974). In: NEGRI, A. I libri del Rogo. Roma: Derive Approdi, 2006.

PEREIRA, L. "O trabalho em causa na 'epidemia depressiva". Tempo social, v. 23, n. 1, São Paulo, 2011.

SIBERTIN-BLANC, G. Politique et État chez Deleuze et Guattari. Essai sur le matérialisme historico-machinique. Paris: PUF, 2013.

VAN CREVEL, M. Ascensão e declínio do Estado. Trad. Jussara Simões. São Paulo: Martins Fontes, 2004.

WACQUANT, L. Punire i poveri. Il nuovo governo dell'insicurezza sociale. Trad. Michele Ménard. Roma: Derive Approdi, 2006. 
